Gut, 1989, 30, 1012-1015

Liver, biliary, and pancreas

\title{
Acid resistant lipase as replacement therapy in chronic pancreatic exocrine insufficiency: a study in dogs
}

\author{
S M GRIFFIN, D ALDERSON, AND J R FARNDON \\ From the Department of Surgery, The Medical School, University of Newcastle upon Tyne, Newcastle upon \\ Tyne
}

SUMMARY Conventional treatment of pancreatic steatorrhoea in man has been unsatisfactory because $90 \%$ of the lipase content of therapy is inactivated by acid in the stomach and large doses of replacement treatment are needed to provide adequate supplementation. An acid stable agent (fungal lipase) was investigated in the treatment of pancreatic deficiency steatorrhoea in 11 pancreatectomised dogs maintained on a fixed dietary intake of fat and treated with pancreatin or fungal lipase. Ten grams (60000 U lipase) of pancreatin was compared with $400 \mathrm{mg}$ (4800 U lipase) of fungal lipase administered with each meal against a no treatment group. There was no significant difference in stool bulk and faecal fat excretion between pancreatin and lipase treated animals. Both groups showed a significant reduction in stool bulk and fat excretion when compared with the no treatment group (p<0.01). A markedly diminished treatment volume, in the form of fungal lipase, is as effective in controlling steatorrhoea as pancreatin and may prove to be a potentially valuable therapy for patients with pancreatic insufficiency.

The most common causes of pancreatic exocrine insufficiency are cystic fibrosis and chronic pancreatitis resulting in two major problems: poor nutrition and considerable social embarrassment. Steatorrhoea is mainly a consequence of failure of digestion and aqueous solubilisation of lipid leading to its malabsorption.

The mainstay of treatment in pancreatic steatorrhoea has been replacement of endogenous pancreatic enzymes by supplements from hog pancreas (pancreatin - Paynes and Byrne). This has often proved unsatisfactory in the long term as many patients require 20 or 30 tablets per meal and still experience the nutritional and social consequences of steatorrhoea. As much as $30000 \mathrm{U}$ lipase are needed with each meal to abolish steatorrhoea. ${ }^{1}$ Most commercial preparations contain about $5000 \mathrm{U}$ of lipase per tablet and do not approach the replacement dosage. Unfortunately, $90 \%$ of the lipase content of pancreatin is inactivated by gastric $\mathrm{acid}^{2}$ and so larger numbers of tablets are required to provide adequate supplementation.

Address for correspondence: Professor J R Farndon, Department of Surgery, University of Bristol, Bristol Royal Infirmary, Bristol BS2 8HW.

Accepted for publication 9 November 1988.
Pancreatin is available in powder, capsules or tablets. Powder, sprinkled on meals, is found to be unpalatable and is poorly tolerated except in very young children. Capsules (gelatin shells containing pancreatin) dissolve in the stomach releasing the powder. Enteric-coating of pancreatin, formulated to dissolve only above a pH of $6^{3}$ (Nutrizym and Pancrex V Forte), is intended to protect pancreatin against intragastric inactivation. This preparation is seldom completely effective as the capsules can remain intact in the stomach until the meal has passed and when the capsules do enter the duodenum the coating may not dissolve because of duodenal hyperacidity $^{4}$ - most patients with pancreatic insufficiency have reduced bicarbonate secretion. Preparations including the microencapsulated pancreatin, designed to release the enzyme in the jejunum, may be ineffective if jejunal acidification is significant. Adjunctive treatment with $\mathrm{H}_{2}$ receptor antagonists can lessen intragastric inactivation of pancreatin and therefore increases lipid digestion and fat solubilisation in the duodenum. ${ }^{5}$ Cimetidine (Smith Kline and French) and pancreatin together are more effective in abolishing steatorrhoea and reducing faecal fat excretion $^{6}$ but in many patients this is unsuccessful. 
Expense, number of tablets required and associated poor patient compliance continue to encourage the search for more satisfactory forms of replacement therapy.

Digestion of fats by pancreatic lipase occurs mainly in the duodenum. Lingual lipase which is acid resistant contributes to this process. ${ }^{7}$ The advantages of acid resistant lipase are obvious but lingual lipase from animal sources is not available. Lipase AP (Paynes and Byrne) is a novel lipolytic enzyme preparation, manufactured by a fermentation process of aspergillus, which is water soluble and stable at a wide range of $\mathrm{pH}$ from 2-10. It is heat stable and non-toxic. The preparation has $12000 \mathrm{U}$ lipase/g weight and its potential therapeutic advantage in reducing exocrine replacement therapy merits evaluation. This study was designed, therefore, to compare the effectiveness of conventional pancreatic enzyme therapy with acid stable fungal lipase (lipase AP) against no treatment in dogs with total pancreatic exocrine insufficiency.

\section{Methods}

\section{DOGS}

Eleven dogs weighing $15-21 \mathrm{~kg}$ were used in the study. All animals underwent total pancreatectomy producing pancreatic exocrine insufficiency. All animals received intrasplenic islet autografts prepared by collagenese digestion of pancreatic tissue to preserve endocrine function. ${ }^{p}$ These animals developed functioning endocrine grafts providing fasting euglycaemia within one month of pancreatectomy. Animals studied preoperatively acted as normal controls (group A). Pancreatectomised animals were assessed on no replacement therapy (group B), on fungal lipase (group C) and on pancreatin (group D). The animals were maintained on a fixed dietary intake which included $46 \mathrm{~g}$ fat per day. The study was designed in a randomised crossover fashion incorporating a different treatment regimen for three week periods. Animals were weighed before and after each period and three day collections of faeces were made and analysed for stool volume and fat content at the completion of each treatment. Animals on less than $10 \mathrm{~g}$ pancreatin had previously been observed to develop steatorrhoea, so $10 \mathrm{~g}$ (60000 U lipase) of pancreatin was compared with $400 \mathrm{mg}$ (4800 U lipase) of fungal lipase given with each meal against no treatment. The stools were stored at $-20^{\circ} \mathrm{C}$ until they were analysed for total fat content by the van der Kamer method." Statistical analysis was performed using the Wilcoxon's rank-sum test for non-parametric paired data and signed rank test for unpaired data. Values indicated in the test are given as medians (range).

\section{Results}

WEIGHT (Table)

Animals observed over a three week period preoperatively showed no significant weight change within a range of $-0.6 \mathrm{~kg}$ to $+0.8 \mathrm{~kg}$. Animals receiving no replacement therapy over a three week period showed significant weight losses of $-0.9 \mathrm{~kg}$ $(-1.7$ to $-0.2 \mathrm{~kg}) \quad(\mathrm{p}<0.01 v$ group $\mathrm{A})$. When receiving fungal lipase or pancreatin the animals did not show significant weight loss compared with preoperative animals.

FAECAL FAT (Fig. 1)

A range of normal values was obtained from normal animals pre-operatively $(9.9-12.3 \mathrm{mmol} / 24 \mathrm{~h})$ with a median value of $10.8 \mathrm{mmol} / 24 \mathrm{~h}$. Faecal fat excretion in group B was significantly raised when compared with normal animals demonstrating considerable fat malabsorption $(p<0 \cdot 01)$. There was no significant difference observed between animals of group $A$ and

Table Weight changes of animals

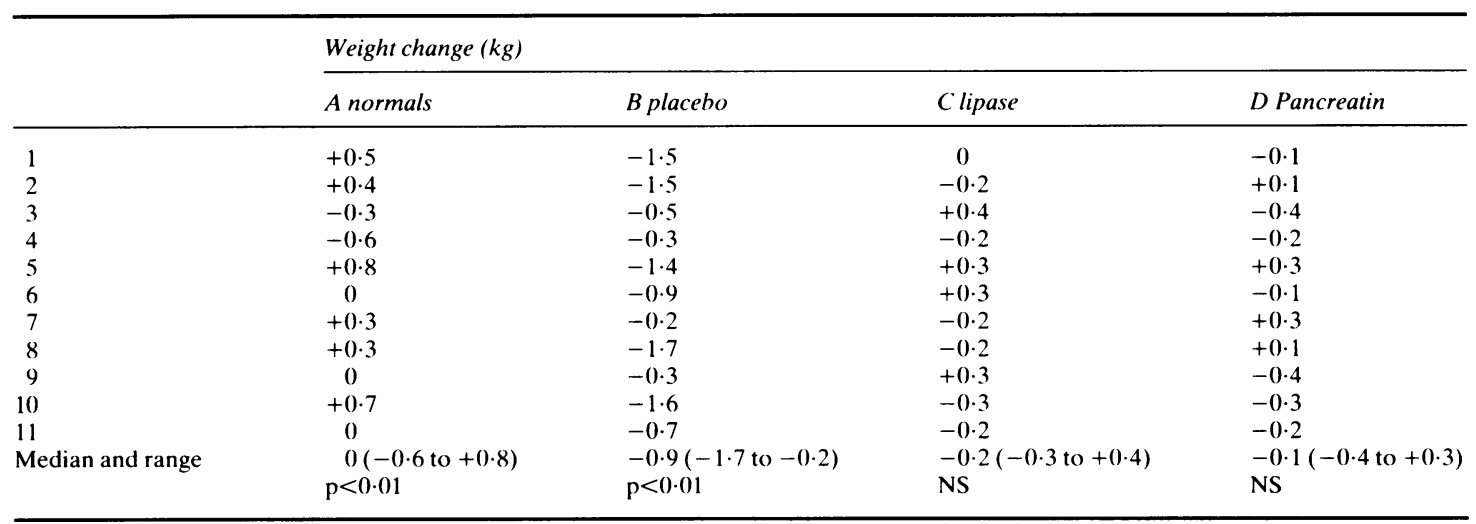




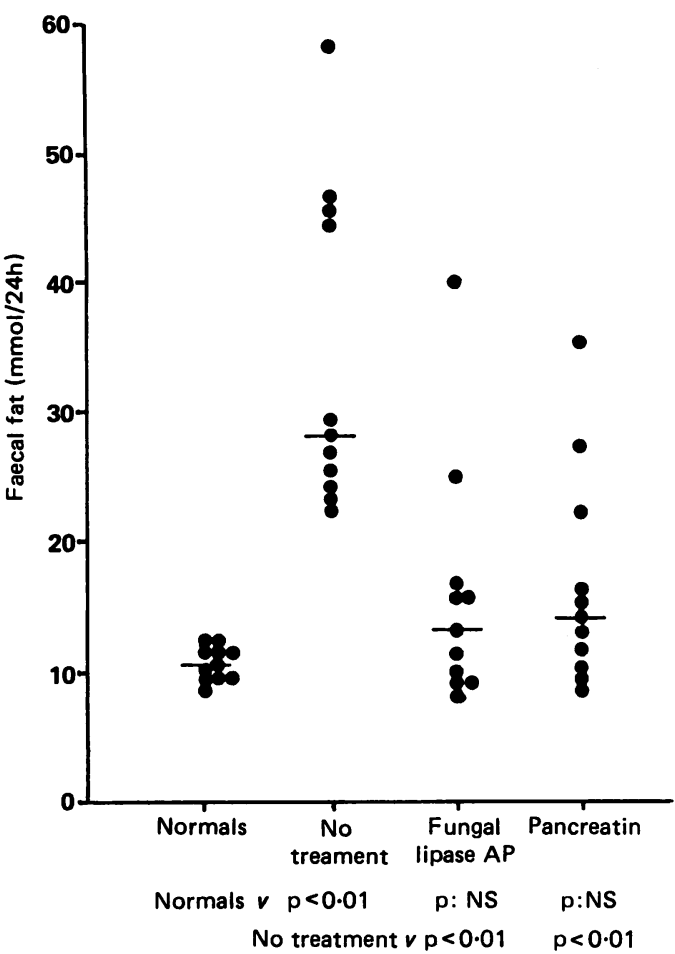

Fig. 1 Faecal fat excretion/24 $h$.

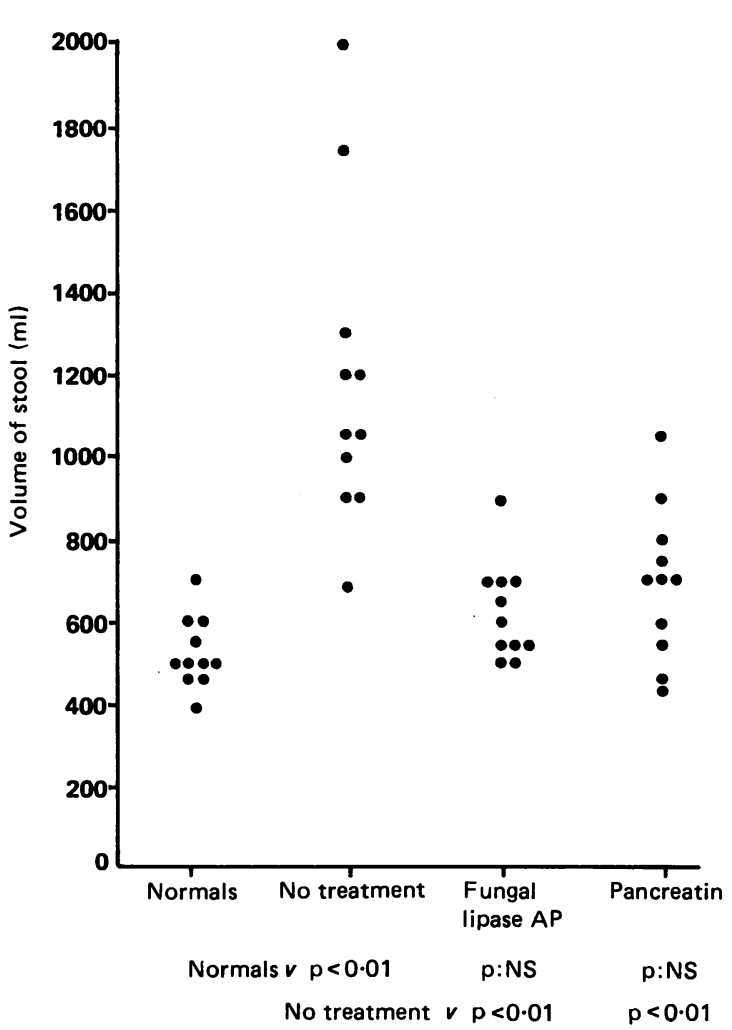

Fig. 2 Stool volume/24h.

With the daily dosages of pancreatin and acid stable lipase, a statistically significant reduction of total faecal fat excretion/day of between 42 and $60 \%$ occurred when comparison was made over a similar period of no treatment. Considerable variations in faecal fat excretion in individual animals were noted, although weight changes were not so obvious. One animal with a mean faecal fat excretion before pancreatectomy of $11 \mathrm{mmol} / 24 \mathrm{~h}$ had concentrations of 40 and $36 \mathrm{mmol} / 24 \mathrm{~h}$ on replacement regimens. This observation may be because of the variation in acid output from the stomach and variable contributions of gastric and small intestinal lipase in different animals.$^{10}$ This is probably a reflection of using a fixed dosage rather than tailoring the replacement therapy and the needs of the individual.

The most significant finding was the demonstration that a very small dose of acid stable lipase $(400 \mathrm{mg})$ was as effective as pancreatin $(10 \mathrm{~g})$ in treating the steatorrhoea of pancreatic exocrine insufficiency in dogs. The study did not evaluate the effects of protein malabsorption, or examine the role of protein binding to bile acids as a cause of steatorrhoea. The results obtained may have considerable clinical implications in man. With the very large quantities of orally ingested conventional preparations of lipase
are inactivated in the acid medium of the stomach. 
pancreatin necessary to replace missing enzymes in children with cystic fibrosis, problems of compliance as well as malabsorption are encountered. Furthermore, pancreatic extract contains high levels of purine and large doses of pancreatin can cause hyperuricaemia which may result in renal damage. ${ }^{11}$ Although the addition of $\mathrm{H}_{2}$ receptor antagonists ${ }^{1213}$ and the development of microencapsulated pancreatin $^{14}$ have improved the situation, the use of a high lipase content preparation which is acid stable may provide patients suffering from cystic fibrosis and chronic pancreatitis with a low dose, effective mode of therapy. Further studies in man would be worthwhile.

\section{References}

1 Dimagno EP. Controversies in the treatment of pancreatic exocrine insufficiency. Dig Dis Sci 1982; 27: 481-4.

2 Dimagno EP. Fate of orally ingested enzymes in pancreatic insufficiency. Comparison of two dose schedules. N Engl J Med 1977; 296: 1318-27.

3 Gow R, Francis P, Bradbear R, Shepherd R. Comparitive study of varying regimens to improve steatorrhoea and creatorrhoea in cystic fibrosis: effectiveness of an enteric coated preparation with and without antacids and cimetidine. Lancet 1981; ii: 1071-4.

4 Zentler-Munro PL. Effect of intrajejunal acidity and aqueous bile acid and lipid concentrations in pancreatic steatorrhoea due to cystic fibrosis. Gut 1984; 25: 500-7.

5 Regan PT, Malagelada TR, Dimagno EP, Glanzman SL, Go VLW. Comparitive effects of antacids, cimeti- dine and enteric coating on the therapeutic response to oral enzymes in severe pancreatic insufficiency. $N$ Engl J Med 1977; 297: 854-88.

6 Zentler-Munro PL, Fine DR, Northfield TC. Mechanism whereby cimetidine enhances pancreatic enzyme therapy. Gastroenterology. 1981; 80: 1323.

7 Hamosh M. Fat digestion in the newborn. Role of lingual lipase and preduodenal digestion. Paediatr Res 1979; 13: 615-22.

8 Griffin SM, Alderson D, Farndon JR. Comparison of harvesting methods for islet transplantation. Br J Surg 1986; 73: 712-5.

9 Van der Kamer JH, Huinink HB, Weyers HA. Rapid method for the determination of fat in faeces. $J$ Biol Chem 1949; 177: 347-55.

10 Blum AL, Linscheer WG. Lipase in canine gastric juice. Proc Soc Exp Biol Med 1970; 135: 565-8.

11 Stapleton FB, Kennedy J, Nousia Arvanitakis S, Linshaw MA. Hyperuricosuria due to high dose pancreatic extract therapy in cystic fibrosis. $N$ Engl $J$ Med 1976; 295: 246-51.

12 Graham DY. Pancreatic enzyme replacement. The effect of antacids or cimetidine. Dig Dis Sci 1982; 27: 485-90.

13 Durie P, Bell L, Linton W, Covey ML, Forstner GG. Effect of cimetidine and sodium bicarbonate on pancreatic replacement therapy in cystic fibrosis. Gut 1980; 21: 778-86.

14 Schneider MU, Knoll-Ruzicka ML, Domschke S, Heptner G, Domschke W. Pancreatic enzyme replacement therapy: comparitive effects of conventional and enteric coated microsopheric pancreatin and acid stable fungal enzyme preparations on steatorrhoea in chronic pancreatitis. Hepatogastroenterology 1985; 32: 97-102. 